\title{
A METHOD FOR PROJECTING AND BLENDING COLORS.
}

By F. R. GORTON, Michigan State Normal College, Ypsilanti.

In the study of color it is often desired to superpose lights of different kinds upon a white screen. Several devices have beer designed for this purpose, but they are, as a rule, complicated and expensive. The following method which is submitted is decidedly effective and can be carried out almost without cost, provided an ordinary projection lantern is at hand.

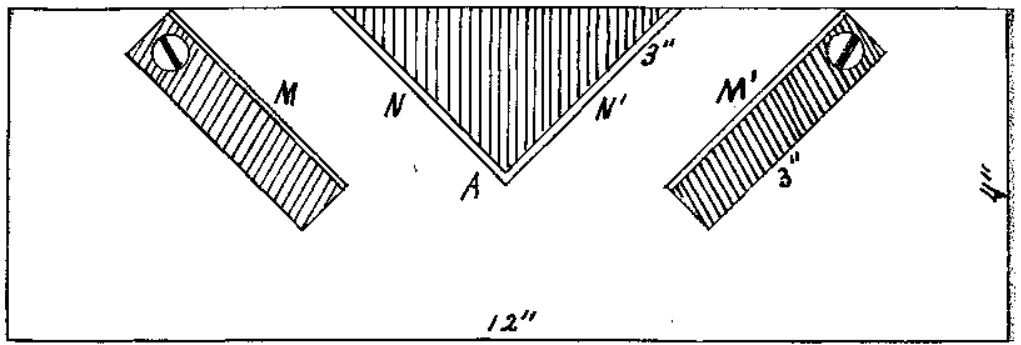

Fig. I.

Four plane mirrors $M, M^{\prime}, N$, and $N^{\prime}$, which are $3 \times 2 \frac{1}{2}$ inches, are mounted on a wooden base $4 \times 12$ inches as shown in Fig. I. Block $\mathrm{A}$ is wedge-shaped, having a right angle at $\mathrm{A}$, and is fastened to the base by means of a screw from below. The blocks to which $\mathrm{M}$ and $\mathrm{M}^{\prime}$ are attached swing with considerable friction about the screws which hold them to the base. Als mirrors are set perpendicular to the base. The mirrors may be held in place with rubber bands or suitable clips.

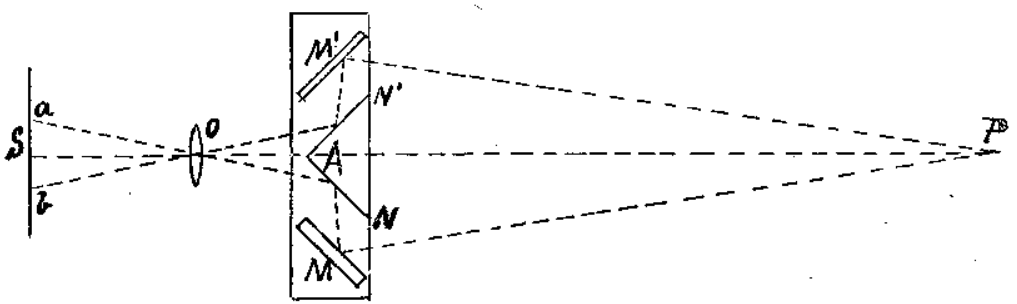

Fig. 2.

The color card is prepared by making two round holes in an piece of cardboard about the size of a lantern slide. These: holes should be about one-half inch in diameter and $I \frac{1}{4}$ inches. between centers and in a horizontal line. The holes are now to be covered with films of the colors that it is desired to super- 
pose, e. g., yellow and blue. If it is desired that the colors be complementary, the films must be selected by actual test.

Fig. 2 shows the method of setting the blending device before the objective of a lantern in order to superpose the colors which come through the color card placed at $a$ and $b$ in the slide carrier $s$. When the light from $a$ falls upon mirror $N$ it is reflected to $M$ and thence to the screen at P. Similarly, light of the other color from $b$ is reflected by the mirrors $\mathrm{N}^{\prime}$ and $\mathrm{M}^{\prime}$ to the screen. Now, by the proper adjustment of $\mathrm{M}$ and $\mathrm{M}^{\prime}$ the color spots can be wholly or partially overlapped on the screen at $P$. If the selection of complementary colors has been well made, the superposed colors will produce white. From a small package of color films offered by apparatus dealers, several pairs of complementary colors can usually be made up.

A modification of the device for work with three colors will be given in another issue of School SCIENCE AND Mathematics.

\section{SUSPENDED T'RANSFORMATIONS.}

\section{By Fredus N. Peters, Central High School, Kansas City, Mo.}

To the student of chemistry one of the most common as well as, at times, one of the most annoying of phenomena, is that of "bumping." Its cause is thoroughly understood, and consequently various methods of entirely preventing or of materially lessening its violence have been devised.

Although this phenomenon is so common and has occasioned so much attention, nevertheless it is possible that not often is it thought of as but an example of a large number of other familiar cases with which it is not associated at all. These may all be classed under the heading, "Suspended Transformations,". a term used by Ostwald in a recent book, an American edition of which has been published by Longmans, Green \& Co.

It has long been known that water as well as various other liquids may, by extreme caution, be cooled sonsiderably below its point of solidification and kept there without change of state for a greater or less length of time; yet, if the smallest particle of the solid phase of the substance be introduced, instantaneous solidification takes place. Supersaturation is an equally familiar phenomenon, or perhaps it may be called the same in another form: Some organic substances are known which 